\title{
Thermodynamic modelling and optimization of a dual pressure reheat combined power cycle
}

\author{
T SRINIVAS \\ School of Mechanical and Building Sciences, Vellore Institute of Technology \\ University, Vellore 632014 \\ e-mail: srinivastpalli@yahoo.co.in
}

MS received 11 September 2008; revised 18 February 2010; accepted 19 July 2010

\begin{abstract}
Heat recovery steam generator (HRSG) plays a key role on performance of combined cycle (CC). In this work, attention was focused on a dual pressure reheat (DPRH) HRSG to maximize the heat recovery and hence performance of CC. Deaerator, an essential open feed water heater in steam bottoming cycle was located to enhance the efficiency and remove the dissolved gasses in feedwater. Each of the heating section in HRSG is solved from the local flue gas condition with an aim of getting minimum possible temperature difference. For high performance, better conditions for compressor, HRSG sections, steam reheater and deaerator are developed. The CC system is optimized at a gas turbine inlet temperature of $1400^{\circ} \mathrm{C}$ due to the present available technology of modern gas turbine blade cooling systems. The exergetic losses in CC system are compared with each other. The present DPRH HRSG model has been compared and validated with the plant and published data.
\end{abstract}

Keywords. Combined cycle; dual pressure; deaerator; exergy analysis; heat recovery steam generator.

\section{Introduction}

Combined cycle (CC) power plants are gaining wider acceptance due to more and more availability of natural gas, now a days, because of their higher overall thermal efficiencies, peaking and two-shifting capabilities, fast start-up capabilities and lesser cooling water requirements. Heat recovery steam generator (HRSG) plays a very important role in recovering the sensible heat of gas turbine exhaust for generating steam, at required pressure and temperature, suitable to steam turbine for further power generation. Heat recovery from the HRSG has to be maximized for higher $\mathrm{CC}$ efficiency. Plant designs need to be adjusted to the specific project parameters to achieve optimum results. The optimization of the HRSG is particularly interesting for the combined plants design in order to maximize the work obtained in the vapor cycle. A detailed optimization of the HRSG is a difficult problem, depending on several variables. These include the number of pressure levels, the pressures, the mass flow ratio, and the inlet temperatures to the HRSG sections. 
Recently, researchers paying much attention towards the heat recovery steam generator to improve the CC performance. Pasha \& Sanjeev (1995) presented a discussion about the parameters which influence the type of circulation and the selection for HRSG. Ongiro et al (1997) developed a numerical method to predict the performance of the HRSG for the design and operation constraints. Ganapathy et al (1988) described the features of the HRSG used in the Cheng cycle system. In this system, a large quantity of steam is injected into a gas turbine to increase electrical power output. Subrahmanyam et al (1995) discussed about the various factors affecting the HRSG design for achieving highest CC efficiency with cheaper, economical and competitive designs and with highest requirements to meet the shorter deliveries. Noelle \& Heyen (2004) designed the once-through HRSG which is ideally matched to very high temperature and pressure, well into the supercritical range. Ragland \& Stenzel (2000) compared four plant designs using natural gas with a view of cost benefits achieved through HRSG optimization. Casarosa et al (2004) determined the operating parameters means both thermodynamic and thermoeconomic analysis, minimizing a suitable objective function by analytical or numerical mathematical methods.

The optimal design and operation of a HRSG is possible with minimization of entropy generation (Nag \& De 1997). Reddy et al (2002) applied second law analysis for a waste HRSG which consists of an economizer, an evaporator and a super heater. Introducing multi pressure steam generation in the HRSG of a combined power plant improves the performance of the plant than that of a corresponding single pressure system (De \& Biswal 2004). Pelster et al (2001) compared the results of a reference CC with the dual and triple pressure HRSGs and also with and without steam reheating models. Bassily $(2005,2007)$ modelled a dual and triple pressure reheat $\mathrm{CC}$ with a preset in constraints on the minimum temperature difference for pinch points, the temperature difference for superheat approach, the steam turbine inlet temperature and pressure, the stack temperature, and the dryness fraction at steam turbine outlet without a deaerator in steam bottoming cycle. Srinivas (2009) suggested an improved location for a deaerator in a triple pressure HRSG. A literature review has shown that the DPRH HRSG has not been modelled and analysed parametrically with a deaerator.

The purpose of this work is to optimize the DPRH HRSG in the CC with a deaerator. The variations in CC performance are plotted with the compressor pressure ratio, gas turbine inlet temperature, HRSG HP, steam reheat pressure and deaerator pressure. From the present thermodynamic modelling, the optimized conditions to air compressor, HP steam, LP steam, steam reheater and deaerator have been developed.

\section{Thermodynamic model of the CC with DPRH HRSG}

The optimized model in HRSG improves the steam generation rate and hence steam turbine output. Schematic flow diagram for CC is shown in figure 1. Simple gas cycle gives higher efficiency at low compressor ratio compared to the intercooled-reheat model and hence in this work simple gas cycle is selected as a topping cycle in CC (Srinivas et al 2007). Figure 2 shows the temperature-entropy diagram for the CC shown in figure 1 . Steam cycle with a reheater is taken as a bottoming cycle in CC. In steam cycle a deaerator is located to gain higher efficiency as well as to remove the dissolved gasses in feed water. Condensate preheater is arranged in the HRSG as a last heat transfer surface to improve the heat recovery.

The temperature-heat transferred diagram for DPRH heat recovery is depicted in figure 3. The CC is modelled with DPRH configuration in HRSG. An attempt has been made to improve 


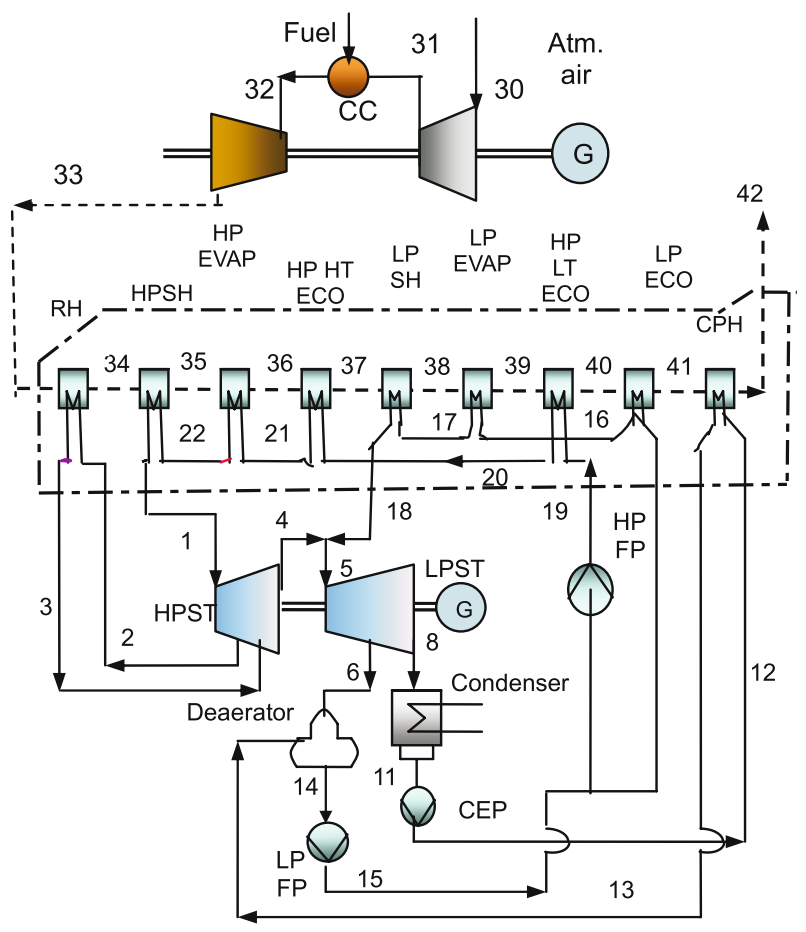

Figure 1. Schematic representation of $\mathrm{CC}$ with a dual pressure HRSG; HP: high pressure; LP: low pressure; HT: high temperature; LT: low temperature; GT: gas turbine; ST: steam turbine; RH: reheater; SH: superheater; EVAP: evaporator; ECO: economizer; CPH: condensate preheater; FP: feed pump; HRSG: heat recovery steam generator; CEP: condensate extraction pump.

the heat recovery with parametric analysis. In this work, steam temperatures and low pressure (LP) are not getting fixed as in a regular method. Those are (except HP pressure and deaerator pressure) determined with the local flue gas temperature in heating sections of HRSG.

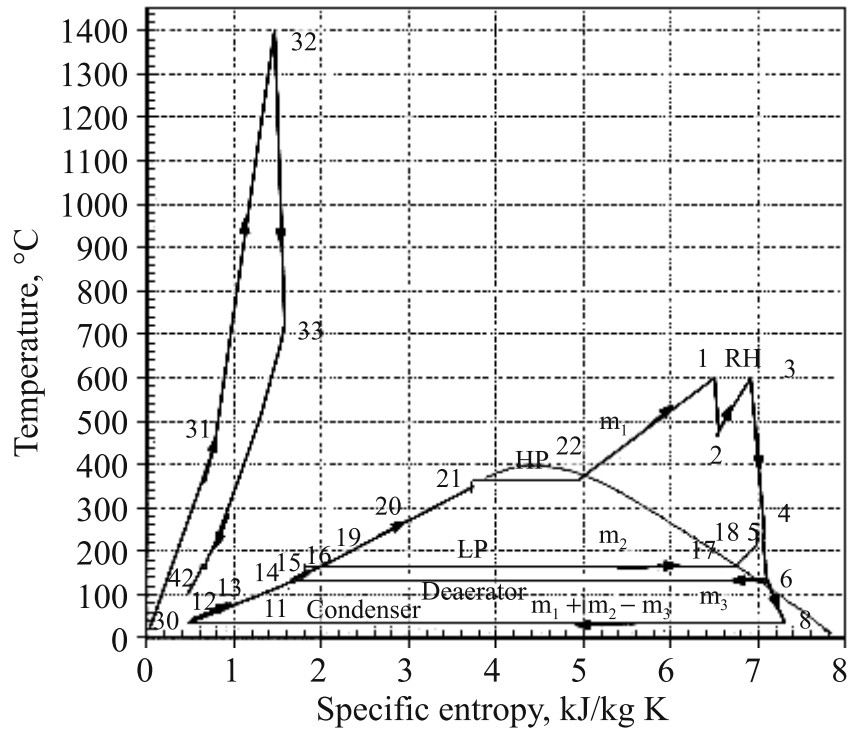

Figure 2. Temperature-entropy diagram of a DPRH CC. 


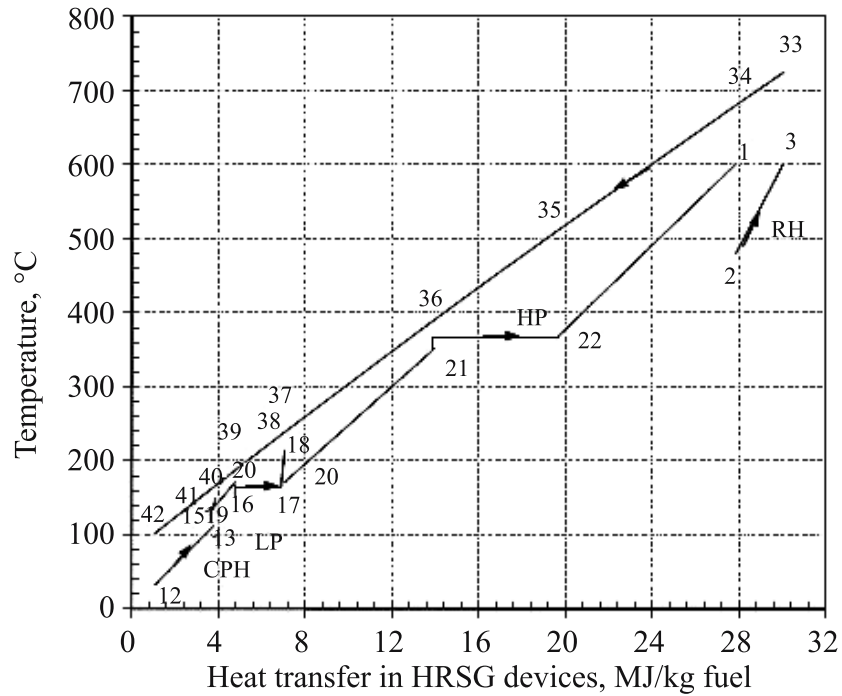

Figure 3. Details of heat recovery in a dual pressure HRSG.

Pinch point (PP)-minimum temperature difference between gas turbine exhaust leaving the evaporator and saturation temperature of steam in evaporators and terminal temperature difference (TTD)-temperature difference between exhaust entry and super heated steam in super heaters are maintained constant. Their choice is the consequence of a compromise between thermodynamic efficiency and investment costs (Franco \& Russo 2002). $15 \mathrm{~K}$ approach point (temperature difference between saturated steam and incoming water) is assumed in economizers.

\section{Thermodynamic analysis of the $\mathrm{CC}$}

The assumptions made for the analysis of the $\mathrm{CC}$ are tabulated in table 1 . The fuel to electricity efficiency of the CC is determined based on the lower heating value $(50,145 \mathrm{~kJ} / \mathrm{kg}$ ) of the fuel. The net work output of CC in percent of standard chemical exergy of the fuel $(52,275 \mathrm{~kJ} / \mathrm{kg})$ is expressed as exergy efficiency of CC (Kotas 1995).

For an isentropic compression process, the change in the entropy for air is zero i.e. $\Delta s=0$. The isentropic efficiency (Eq. 1 and 2) for compressor and gas turbine is determined from pressure ratio $\left(r_{c}\right)$, specific heat ratio $(\gamma)$ and polytropic state efficiency $\left(\eta_{\infty}\right)$.

$$
\begin{aligned}
& \text { Isentropic efficiency of compressor, } \eta_{c}=\frac{r_{c}^{\left(\frac{\gamma-1}{\gamma}\right)}-1}{r_{c}^{\left(\frac{\gamma-1}{\gamma \eta \infty c}\right)}-1} \text {. } \\
& \text { Isentropic efficiency of gas turbine, } \eta_{g t}=\frac{1-\left(\frac{P_{33}}{P_{32}}\right)^{\frac{\eta_{\infty} g t}{\gamma}(\gamma-1)}}{1-\left(\frac{P_{33}}{P_{32}}\right)^{\frac{(\gamma-1)}{\gamma}}} \text {. }
\end{aligned}
$$

In Eq. (1) and (2), $\eta_{\infty c}$ and $\eta_{\infty g t}$ are the polytrophic efficiencies of compressor and gas turbine respectively. For an isentropic compression process, the change in entropy for air is 
Table 1. Assumptions made for thermodynamic evaluation of HRSG in CC.

Atmospheric condition

Gas cycle pressure ratio and maximum temperature

Inlet condition for HP steam turbine

TTD between flue gas and superheated steam

Approach point (AP) in LP and HP economizers

Condenser pressure

Steam reheat pressure

Pinch Point (PP) - minimum temperature differences between

the flue gas and the steam in the evaporators

Degree of superheat (DSH) in superheater

Polytrophic stage efficiency for compressor and gas turbine

Isentropic efficiency of steam turbine

Generator efficiency

Pressure drop in combustion chamber

Pressure drop in HRSG, deaerator and condenser is neglected

Heat loss in HRSG, turbines, condenser, and deaerator is

\author{
$25^{\circ} \mathrm{C}$ and 1.01325 bar \\ 14.5 and $1400^{\circ} \mathrm{C}$ \\ 200 bar, $600^{\circ} \mathrm{C}$ \\ 25 \\ 15 \\ $0.05 \mathrm{bar}$ \\ 50 percent of HP pressure \\ 25
}

50

85 percent

90 percent

95 percent

5 percent

zero, i.e. $\Delta s=0$.

$$
\begin{aligned}
& s_{\mathrm{O}_{2}, 31^{\prime}}-s_{\mathrm{O}_{2}, 30}+3.76\left(s_{\mathrm{N}_{2}, 31^{\prime}}-s_{\mathrm{N}_{2}, 30}\right) \\
& \quad-\mathrm{R}\left[\ln \left(0.21 \times \frac{P_{31}}{P_{30}}\right)+3.76 \times \ln \left(0.79 \times \frac{P_{31}}{P_{30}}\right)\right]=0 .
\end{aligned}
$$

In Eq. (3), ' $R$ ' is the universal gas constant. The temperature of air after isentropic compression is estimated from the iteration of entropy change equation in compressor (Eq. 3). Then the actual temperature of compressed air is iterated from compressor isentropic efficiency $\left(\eta_{c}\right)$ and enthalpies.

The combustion equation in gas turbine combustion chamber is

$$
\mathrm{CH}_{4}+x\left(\mathrm{O}_{2}+3 \cdot 76 \mathrm{~N}_{2}\right) \rightarrow \mathrm{CO}_{2}+2 \mathrm{H}_{2} \mathrm{O}+(x-2) \mathrm{O}_{2}+3 \cdot 76 x \mathrm{~N}_{2} .
$$

In combustion equation (Eq. 4), ' $x$ ' is the amount of air to be supplied at a fixed adiabatic flame temperature. The energy balance equation for combustion chamber (Eq. 5) results the value of ' $x$ ' (Eq. 6).

The energy balance equation in gas turbine combustion chamber,

$$
\begin{aligned}
& \left(h_{f, \mathrm{CH} 4}+h_{\mathrm{CH}_{4}}\right)+x\left(h_{\mathrm{O}_{2}}+3 \cdot 76 h_{\mathrm{N}_{2}}\right)_{31} \\
& \quad=\left(h_{f, \mathrm{CO}_{2}}+h_{\mathrm{CO}_{2}}\right)_{32}+2\left(h_{f, \mathrm{H}_{2} \mathrm{O}}+h_{\mathrm{H}_{2} \mathrm{O}}\right)_{32}+(x-2) h_{\mathrm{O}_{2}, 32}+3 \cdot 76 x h_{\mathrm{N}_{2}, 32} .
\end{aligned}
$$

From the above equation,

$$
x=\frac{\left(h_{f, \mathrm{CH} 4}+h_{\mathrm{CH}_{4}}\right)-\left(h_{f, \mathrm{CO}_{2}}+h_{\mathrm{CO}_{2}}\right)_{32}-2\left(h_{f, \mathrm{H}_{2} \mathrm{O}}+h_{\mathrm{H}_{2} \mathrm{O}}\right)_{32}+2 h_{\mathrm{O}_{2}, 32}}{h_{\mathrm{O}_{2}, 32}+3 \cdot 76 h_{\mathrm{N}_{2}, 32}-\left(h_{\mathrm{O}_{2}}+3 \cdot 76 h_{\mathrm{N}_{2}}\right)_{31}} .
$$

The entropy change for isentropic expansion in the gas turbine is

$$
\Delta s=0=s_{32}-s_{33^{\prime}},
$$


where

$$
\begin{aligned}
s_{32}= & {\left[s_{\mathrm{CO}_{2}}+2 s_{\mathrm{H}_{2} \mathrm{O}}+(x-2) s_{\mathrm{O}_{2}}+3.76 x s_{\mathrm{N}_{2}}\right]_{32} } \\
& -R\left[\ln \left(\frac{1}{N_{P}} \times \frac{P_{32}}{P_{0}}\right)+2 \times \ln \left(\frac{2}{N_{P}} \times \frac{P_{32}}{P_{30}}\right)+(x-2)\right. \\
& \left.\times \ln \left(\frac{(x-2)}{N_{P}} \times \frac{P_{32}}{P_{0}}\right)+3.76 x \times \ln \left(\frac{3 \cdot 76 x}{N_{P}} \times \frac{P_{32}}{P_{0}}\right)\right]
\end{aligned}
$$

and

$$
\begin{aligned}
s_{33^{\prime \prime}}= & {\left[s_{\mathrm{CO}_{2}}+2 s_{\mathrm{H}_{2} \mathrm{O}}+(x-2) s_{\mathrm{O}_{2}}+3.76 x s_{\mathrm{N}_{2}}\right]_{33^{\prime}} } \\
& -R\left[\ln \left(\frac{1}{N_{P}} \times \frac{P_{33}}{P_{0}}\right)+2 \times \ln \left(\frac{2}{N_{P}} \times \frac{P_{33}}{P_{30}}\right)+(x-2)\right. \\
& \left.\times \ln \left(\frac{(x-2)}{N_{P}} \times \frac{P_{33}}{P_{0}}\right)+3.76 x \times \ln \left(\frac{3 \cdot 76 x}{N_{P}} \times \frac{P_{33}}{P_{0}}\right)\right] .
\end{aligned}
$$

The entropy change in the gas turbine is determined from Eq. (8) and (9). $N_{P}$ is the total number chemical elements in the products of combustion. The iteration of entropy change equation (Eq. 7), results the gas turbine exhaust temperature. Then the actual temperature is iterated from the gas turbine isentropic efficiency $\left(\eta_{g t}\right)$ and enthalpies.

The modelling of CC system is started with an arbitrarily chosen deaerator pressure. The exit state of deaerator is saturated liquid after direct mixing of bled steam with feed water. The LP pressure is evaluated from the saturation temperature. The saturation temperature of steam is a function of gas temperature, TTD and DSH (Eq. 10). The steam flow rate and gas temperature in the heating devices (HP, LP and deaerator) are determined from the heat balance equations.

The saturation temperature of the LP evaporator,

$$
\mathrm{T}_{\mathrm{LPsat}}=T_{\mathrm{LPexout}}-\mathrm{TTD}_{\mathrm{LP}}-\mathrm{DSH}_{\mathrm{LP}} \text {. }
$$

At HP evaporator the flue gas outlet temperature, $\mathrm{T}_{36}=\mathrm{T}_{\mathrm{HPsat}}+\mathrm{PP}_{\mathrm{HP}}$

At LP evaporator the flue gas outlet temperature, $\mathrm{T}_{39}=\mathrm{T}_{\mathrm{LPsat}}+\mathrm{PP}_{\mathrm{LP}}$

At HPHT economizer, water outlet temperature, $\mathrm{T}_{21}=\mathrm{T}_{\mathrm{HPsat}}-\mathrm{AP}_{\mathrm{HP}}$

At LP economizer, water outlet temperature, $\mathrm{T}_{16}=\mathrm{T}_{\mathrm{LPsat}}-\mathrm{AP}_{\mathrm{LP}}$.

The work interactions in gas and steam cycles are calculated to unit mass of fuel. To determine exergetic losses, the irreversibilities associated in all the components to be estimated for exergy analysis. In this analysis, the efficiency and losses are determined for $1 \mathrm{kmol}$ of fuel.

The chemical availability or exergy of a fuel is the maximum theoretical work obtainable by allowing the fuel to react with the oxygen from environment to produce environmental components of carbon dioxide and water vapor. When the difference in availability between states of same composition is evaluated, chemical contribution cancels, leaving just thermo mechanical contributions. This will be the case while doing availability analyses for compressors and turbines. However, the chemical contribution plays a main role in fuel gas combustor. 
The chemical and physical exergy components are determined at each state by using the following equations.

$$
\text { Chemical exergy, } e_{p h}=\sum_{k} n_{k} \varepsilon_{k}^{0}+R T_{0} \Sigma_{k} n_{k} \ln \cdot\left[P \cdot x_{k}\right],
$$

where $x_{k}$ is the mole fraction of $k^{\text {th }}$ component

$$
\begin{aligned}
& \text { Physical exergy, } e_{p h}=h-\Sigma_{k} T_{0} s_{k} . \\
& \text { Exergy, } e=e_{c h}+e_{p h} .
\end{aligned}
$$

The exergetic loss associated in each component is determined from exergy balance for the component/process. The exergetic loss due to mixing of fluids is added to the HRSG exergetic loss. The exergy efficiency is defined as the ratio of net work output from $\mathrm{CC}$ to the availability of fuel (Eq. 18).

$$
\text { Exergy efficiency of CC, } \eta_{2, c}=\left(\frac{\varepsilon_{\mathrm{CH}_{4}}^{0}-i_{\text {total }}}{\varepsilon_{\mathrm{CH}_{4}}^{0}}\right) \times 100 \text {. }
$$

\section{Results and discussions}

CC with DPRH HRSG has been studied parametrically to find the maximum obtainable output and efficiency from the power system. Deaerator pressure at which steam is trapped to heat the feed water is a key parameter to get the optimum heat recovery from the exhaust. Sensitivity analysis has been carried out with the gas turbine inlet temperature, compressor pressure ratio, steam reheat pressure ratio and deaerator temperature ratio. All the plots are prepared at an air flow rate of $625 \mathrm{~kg} \mathrm{~s}^{-1}$. Deaerator location is expressed in dimensionless form, defined as the ratio of difference in saturation temperatures of deaerator and condenser to the overall saturation temperature difference in the bottom cycle (Eq. 19).

$$
\text { Deaerator temperature ratio, } \theta_{\text {deae }}=\frac{\mathrm{T}_{\text {deae,sat }}-\mathrm{T}_{\text {cond,sat }}}{\mathrm{T}_{\mathrm{HP}, \mathrm{sat}}-\mathrm{T}_{\text {cond,sat }}} .
$$

Figure 4 shows the effect of compressor pressure ratio for different values of gas turbine inlet temperature on CC power and efficiencies. In all the following figures (a) net electric power output, (b) fuel to electricity efficiency i.e. energy efficiency and (c) exergy efficiency are developed against the CC key parameters. The difference in exergy of fuel and total exergetic losses gives the net work output (Eq. 18). The heating value of fuel is slightly less than the exergy of fuel. Generator efficiency has been considered in determining the fuel to electricity efficiency. Therefore, both the fuel to electricity efficiency and exergy efficiency of CC are nearer to each other as shown in all the plots. The compressor pressure ratio is varied in such a way that the gas turbine exit temperature should not be less than $600^{\circ} \mathrm{C}$. Due to limitation of steam maximum temperature $\left(600^{\circ} \mathrm{C}\right)$, the resulted range of feasible compressor pressure ratio is 8 to 12 at a gas turbine inlet temperature of $1200^{\circ} \mathrm{C}$. This range is 10 to 18 at $1300^{\circ} \mathrm{C}$ and 14 to 26 at $1400^{\circ} \mathrm{C}$. The gas inlet temperature to HRSG is high at low pressure ratio and due to this reason; more quantity of steam can be generated in HRSG. This results in high output and efficiencies as shown. The pressure ratio corresponding to high performance increases from 10 to 14 with an increase in gas turbine inlet temperature of $1200^{\circ} \mathrm{C}$ to $1400^{\circ} \mathrm{C}$. 

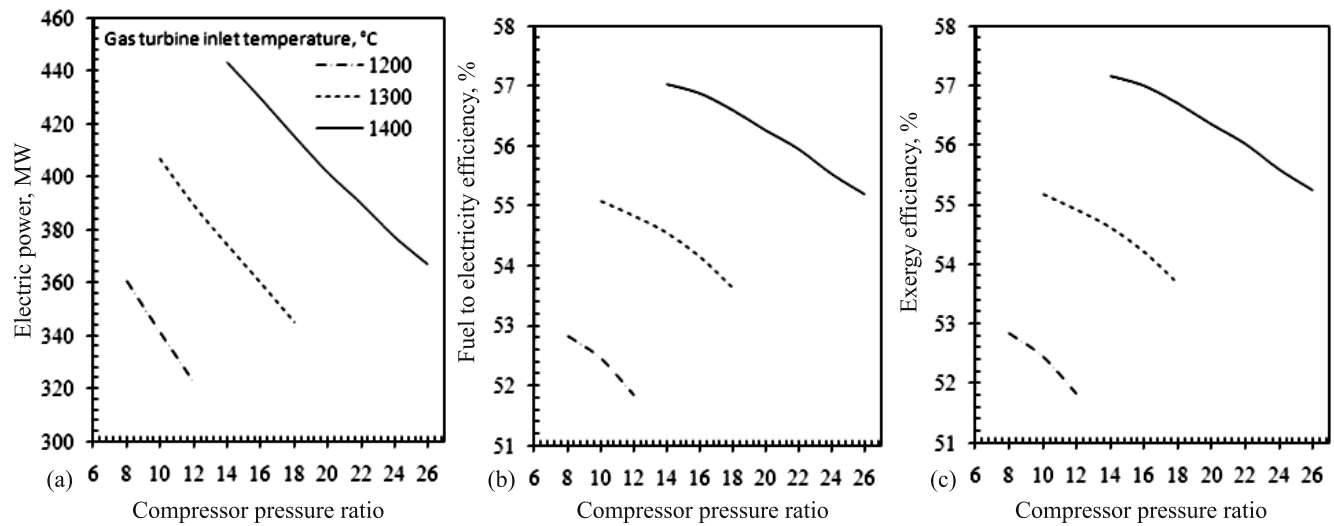

Figure 4. The feasible compressor pressure ratio at different gas turbine inlet temperatures and its effect on CC performance.

Figure 5 presents the effect of compressor pressure ratio with HRSG HP on CC performance. The $\mathrm{H}$ combined cycle system will be the first power plant to achieve 60 percent efficiency and will operate at high temperature of $1430^{\circ} \mathrm{C}$. This has been achieved by advances in materials and cooling system technology. Therefore, all the performance characteristics curves are developed at a gas turbine inlet temperature of $1400^{\circ} \mathrm{C}$. At $1400^{\circ} \mathrm{C}$, the compressor pressure ratio is varied from 14 to 26 as discussed in the previous section. HRSG HP is varied from 50 to 200 bar. The power output is high at low pressure ratio irrespective of HRSG HP in the preselected pressure ratio range (14-26). But with respect to energy and exergy efficiencies, the optimum pressure ratio decreases with an increase in HRSG HP.

The effect of steam reheat pressure expressed in a fraction of HRSG HP has been depicted in Figure 6 at different values of HRSG HP. The optimum steam reheat pressure ratio increases with an increase in HRSG HP. But due to the limitation in dryness fraction (0.8) at steam turbine exit, the steam reheat pressure ratio is limited to 0.5 in the present work at HRSG HP of 200 bar.
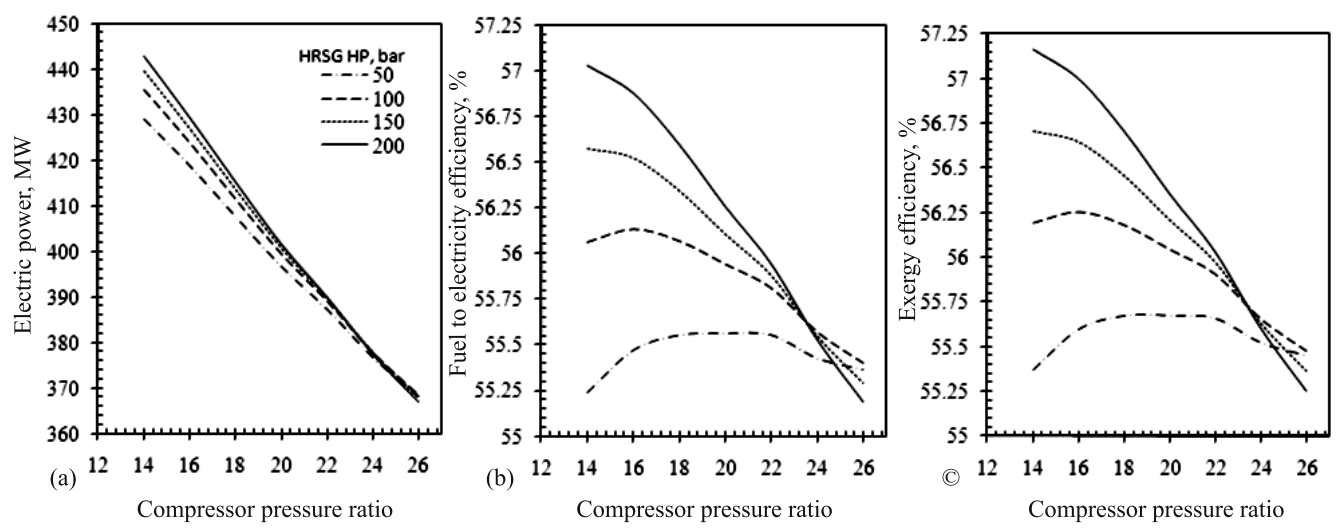

Figure 5. Effect of compressor pressure ratio on performance of $\mathrm{CC}$ for different values of HRSG HPs at a gas turbine inlet temperature of $1400^{\circ} \mathrm{C}$. 

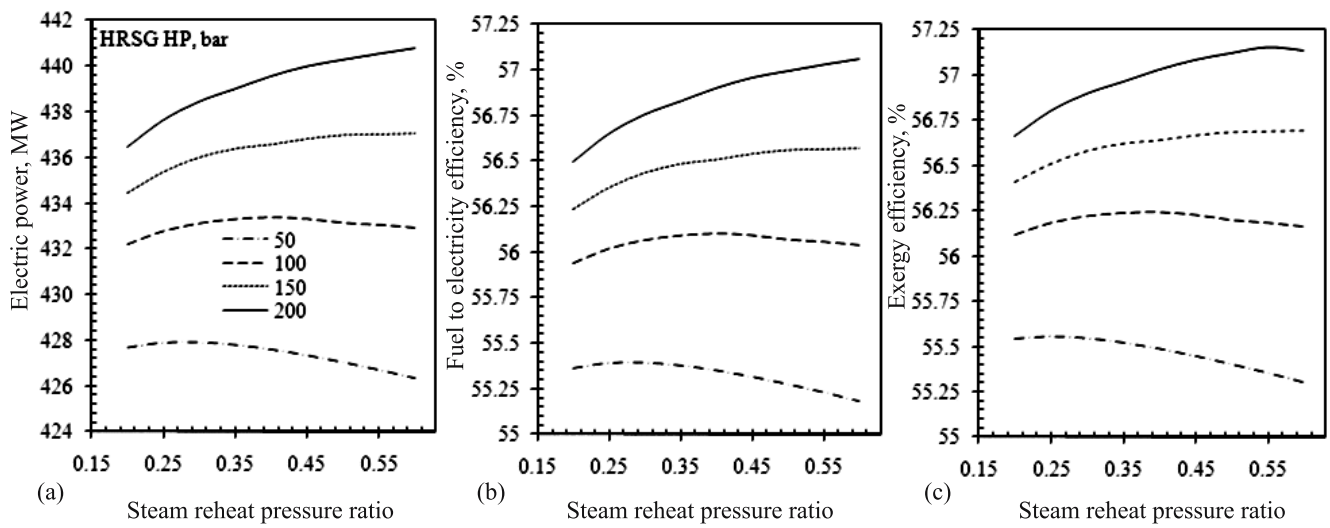

Figure 6. CC performance vs. steam reheat pressure ratio with HRSG HP.

Figure 7 generates the effect of deaerator temperature ratio as defined in Eq. (19) on CC performance at different sets of HRSG HPs. The optimum deaerator temperature ratio is found in between 0.25 and 0.3 with the variation of HRSG HP from 50 bar to 200 bar.

Figure 8 compares the exergetic losses of cycle components in percent of standard chemical exergy of fuel. The second low evaluation is useful to identify the major losses to focus the attention on the weak areas for further improvements. The major exergetic loss occurs in gas turbine combustion chamber in the order of 27.5 percent and the minor exergetic loss is in deaerator. With a steam injection in combustion chamber, this major exergetic loss can be decreased (Srinivas et al 2007, 2008). Next to GTCC, considerable level of exergy is destroyed in compressor, gas turbine, HRSG and exhaust in the range of 2 to 3 percent.

The present DPRH HRSG model results are compared and validated with ABB-Alstom, greatest manufacturers of $\mathrm{CC}$ plants in the world and the literature results. This comparison is presented in table 2. The inlet conditions for DPRH HRSG are chosen from ABB plant. However, the present HRSG layout with a deaerator adopted here are quite different from those of comparison. The main differences we can find between the plant data and present work are the value of the HRSH HP and reheat pressures. It can be supposed that all the other
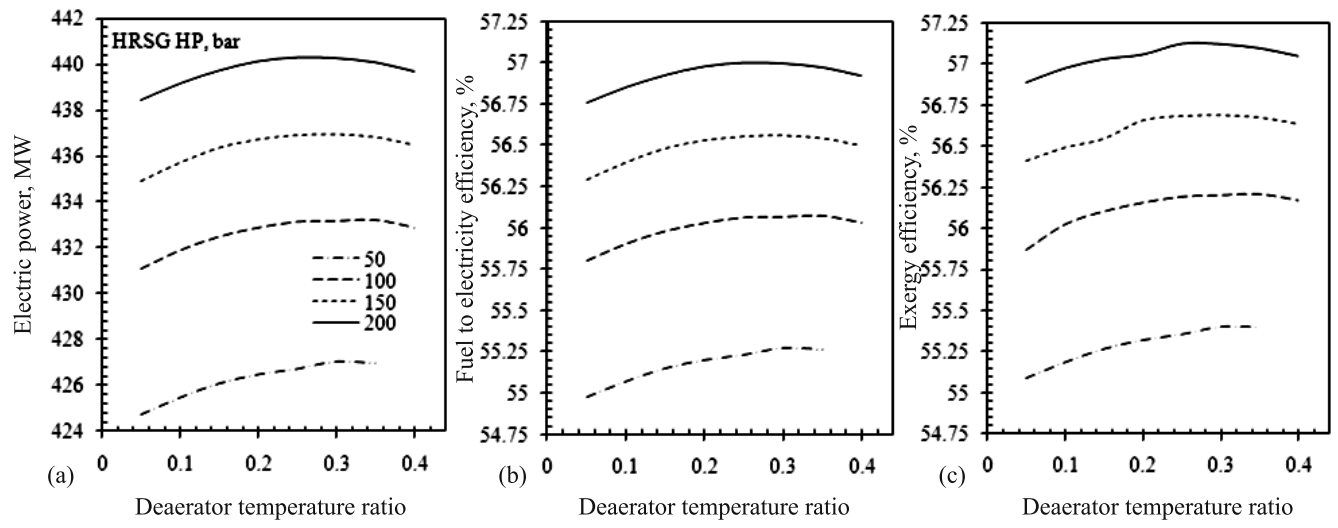

Figure 7. CC performance vs. deaerator temperature ratio with HRSG HP. 


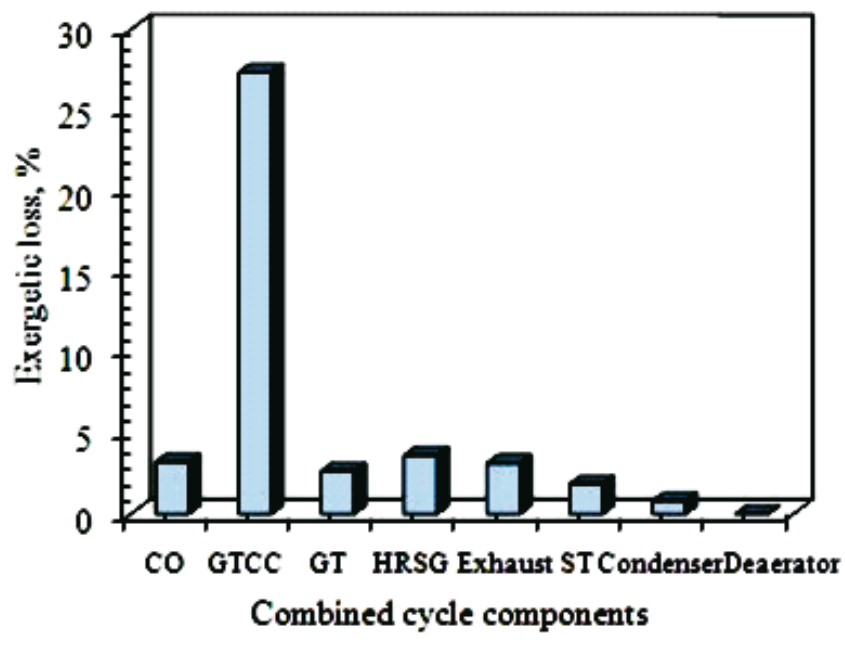

Figure 8. Comparison of exergetic losses in $\mathrm{CC}$ components in per cent of standard chemical exergy input of fuel.

differences that arise from the comparison (pressures and the flow rates) are a consequence of this primary characteristic that influences the properties of the thermal cycles deeply. In the present work, the HRSG LP is more than from the observations. It is due to inclusion of deaerator at a pressure below the LP level. Remaining all the results are in agreement with the plant and literature results.

\section{Conclusions}

In a CC power generation system, a DPRH HRSG has been critically examined. For a given set of gas turbine inlet temperature, the feasible range of compressor pressure ratio has been developed. For a maximum steam temperature of $600^{\circ} \mathrm{C}$, the feasible compressor ratios are $8-12,10-18$ and $14-26$ for a gas turbine inlet temperature of $1200^{\circ} \mathrm{C}, 1300^{\circ} \mathrm{C}$ and $1400^{\circ} \mathrm{C}$

Table 2. Comparison of heat recovery details with the plant data and published results at $\mathrm{T}_{g, \text { HRSGin }}=650^{\circ} \mathrm{C}$ and $m_{g}=386.7 \mathrm{~kg} \mathrm{~s}^{-1}$.

\begin{tabular}{|c|c|c|c|}
\hline & $\mathrm{ABB}$ & $\begin{array}{c}\text { Franco \& } \\
\text { Russo (2002) }\end{array}$ & Present work \\
\hline $\mathrm{P}_{\mathrm{HP}}$, bar & 164 & 220 & 200 \\
\hline $\mathrm{T}_{\mathrm{HPSH}},{ }^{\circ} \mathrm{C}$ & 563 & 556 & 550 \\
\hline$m_{\mathrm{HP}}, \mathrm{kg} \mathrm{s}^{-1}$ & 58.9 & $67 \cdot 3$ & $57 \cdot 3$ \\
\hline $\mathrm{P}_{\mathrm{RH}}$, bar & $38 \cdot 2$ & $69 \cdot 7$ & 100 \\
\hline $\mathrm{T}_{\mathrm{RHin}},{ }^{\circ} \mathrm{C}$ & - & 374 & 434 \\
\hline $\mathrm{T}_{\text {RHout }},{ }^{\circ} \mathrm{C}$ & 562 & 556 & 550 \\
\hline $\mathrm{P}_{\mathrm{LP}}$, bar & 6.9 & 1.6 & $12 \cdot 8$ \\
\hline $\mathrm{T}_{\text {LPSH }},{ }^{\circ} \mathrm{C}$ & 323 & sat & 242 \\
\hline$m_{\mathrm{LP}}, \mathrm{kg} \mathrm{s}^{-1}$ & 11.4 & 4.53 & 9.76 \\
\hline $\mathrm{W}_{\text {net, sc }}, \mathrm{MW}$ & 97 & $67 \cdot 3$ & 87 \\
\hline
\end{tabular}


respectively. Out of this range, the optimum compressor pressure ratio decreases with an increase in HRSG HP. The optimum deaerator temperature ratio is suggested at 0.25 to 0.3 .

\section{Nomenclature}
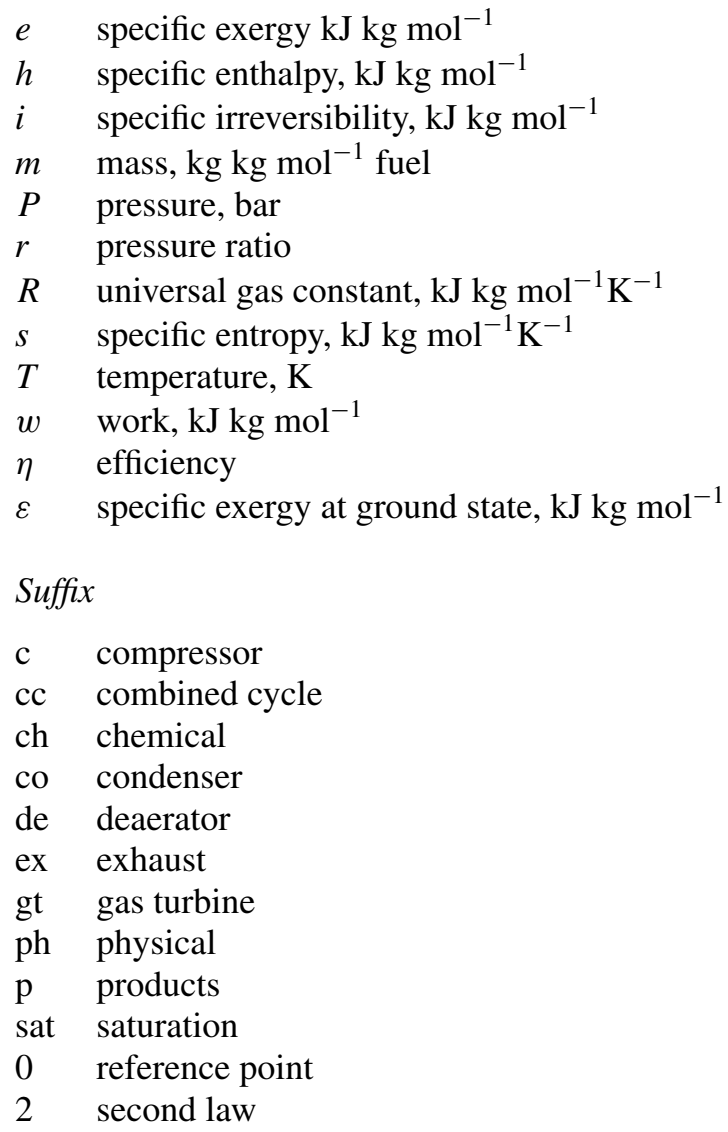

\section{References}

Bassily A M 2005 Modelling, numerical optimization, and irreversibility reduction of a dual-pressure reheat combined cycle. Applied Energy 81: 127-151

Bassily A M 2007 Modelling, numerical optimization, and irreversibility reduction of a triple-pressure reheat combined cycle. Energy 32(5): 778-794

Casarosa F, Donatini, Franco A 2004 Thermoeconomic optimization of heat recovery steam generators operating parameters for combined plants. Energy 29: 389-414

De S, Biswal S K 2004 Performance improvement of a coal gasification and combined cogeneration plant by multi-pressure steam generation. Applied Thermal Engineering 24: 449-456

Franco A, Russo A 2002 Combined cycle plant efficiency increase based on the optimization of the heat recovery steam generator operating parameters. Inter. J. Thermal Sci. 41(9): 843-859

Ganapathy V, Heil B, Rentz J 1988 Heat recovery steam generator for Cheng cycle application, In: B L Williams (ed.) 3rd edition. Industrial Power Conference: 61-65 (No. 100283)

Kotas T J 1995 The Exergy method of thermal plant analysis. Malabar, FL Krieger publishing company 
Nag P K, De S 1997 Design and operation of a heat recovery steam generator with minimum irreversibility. Appl. Thermal Eng. 17(4): 385-391

Noelle M, Heyen G 2004 Mathematical modelling and design of an advanced once-through heat recovery steam generator. Computers and Chemical Eng. 28: 651-660

Ongiro A, Ugursal V I, Taweel A M, Walker J D 1997 Modelling of heat recovery steam generator performance. Appl. Thermal Eng. 17(5): 427-446

Pasha A, Sanjeev J 1995 Combined cycle heat recovery steam generators optimum capabilities and selection criteria. Heat Recovery systems \& CHP 15(2): 147-154

Pelster S, Favrat D, Spakovsky M R 2001 Thermoeconomic and environomic modelling and optimization of the synthesis, design, and operation of combined cycles with advanced options. ASME Journal for Gas Turbines and Power 123: 717-726

Ragland A, Stenzel W 2000 Combined cycle heat recovery optimization. Proceedings of 2000 International Joint Power Generation Conference, Miami Beach, Florida, 1-6, July 23-26

Reddy B V, Ramkiran G, Ashok Kumar K, Nag P K 2002 Second law analysis of a waste heat recovery steam generator. Inter. J. Heat and Mass Transfer 45: 1807-1814

Srinivas T 2009 Study of a deaerator location in triple pressure-reheat combined power cycle. Energy 34(9): 1364-1371

Srinivas T, Gupta A V S S K S, Reddy B V 2007 Performance simulation of 210 MW natural gas fired combined cycle power plant. J. Energy, Heat and Mass Transfer 29: 61-82

Srinivas T, Gupta A V S S K S, Reddy B V 2007 Parametric simulation of steam injected gas turbine combined cycle. J. Power and Energy, Proceedings of the Institution of Mechanical Engineers Part A 221(7): 873-883

Srinivas T, Gupta A V S S K S, Reddy B V 2008 Sensitivity analysis of STIG based combined cycle with dual pressure HRSG. Inter. J. Thermal Sci. 47(9): 1226-1234

Subrahmanyam N V R S S, Rajaram S, Kamalanathan N 1995 HRSGs for combined cycle power plants. Heat Recovery Systems \& CHP 15(2): 155-161 